\title{
Planning in urban flood prone areas: Focus on six principles to reduce urban vulnerability
}

\author{
Anne-Laure Moreau ${ }^{1}$ \\ ${ }^{1}$ CEPRI, European Centre for Flood risk Prevention, BP 2019, 45010 Orléans cedex 1, France
}

\begin{abstract}
CEPRI's thinking on the subject begins with the postulate that in densely urbanised cities the future of flood prone areas cannot be reduced to two alternatives: not constructing or continuing to construct as was done over the past decades, i.e. without taking into account the presence of the risks of flooding (overflowing of waterways, coastal flooding, storm water runoff, etc.). It seems that there exists a third possibility: that of developing cities intelligently, taking account of their environment and of the associated risks. Backed up with European urban projects currently being researched or that have been realised, CEPRI has identified six principles making it possible to take into account the risks of flooding in city planning.
\end{abstract}

\section{Context}

The subject of urbanisation in flood prone areas in the process of urban renewal is currently being vigorously discussed for several reasons.

\subsection{Cities are constructed and continue to be constructed along rivers and at the seaside}

It's an established fact that our cities have for the most part been developed along waterways and at the seaside in the course of history for economic, political and social reasons.

While some countries, such as France, have developed legal tools to limit urbanisation in flood prone areas (foreseeable natural hazards prevention plans called "PPR"), building in these areas remains nonetheless possible today. Thus, in the Paris area, more than 100,000 housing units, $85 \%$ of them in collective housing, have been built in flood prone areas since the 1980s, a period during which the national policy on managing the risks of flooding increased [1].

Moreover, housing alongside waterways is attractive, having a quality of life sought by the population, particularly in France. This population usually underestimates the risk and that exposure of one's lodging to the risk does not show up in the price of sale of real estate in flood prone areas. For example, on the coastal area in the north of France (Nord-Pas-de-Calais), the prices of flats located in zones having a strong to very strong risk are on the average $25 \%$ higher than those of comparable flats located in flood prone areas and thus farther away from the seaside [2].

\footnotetext{
${ }^{\mathrm{a}}$ Corresponding author: anne-laure.moreau@cepri.net
}

\subsection{Densification in flood prone areas is encouraged}

Numerous sectors located alongside rivers or near the sea in the centre of Western cities are floodable and oftentimes wastelands. Witnesses of an industrial activity that contributed to the development of cities such as Amsterdam, Hamburg, Bordeaux, Frankfort, Rotterdam or Mainz, these areas are currently being rezoned and usually come with heavy constraints with regard to pollution abatement as well as with flooding hazards. In territories that are already highly urbanised, these sectors are quite often the only ones that still enable the city to renew itself and offer its inhabitants new urban functions (housing, recreational areas and city parks along waterways, for example).

\subsection{Flood protection structures (levees) are not always infallible}

Numerous territories are protected by levees following the example of the Netherlands, $26 \%$ of whose territory lies beneath sea level and $60 \%$ of which is threatened by coastal flooding and the overflowing of rivers. Out of 16 million inhabitants, only 100,000 do not benefit from the protection of dikes and dunes [3]. France is also a country which is well provided with dikes. In 2014 , around $9,000 \mathrm{~km}$ of dikes were counted protecting against overflows of waterways or coastal flooding [4].

However, numerous examples of dike breaches have weakened the basis of this policy. Whether it is in France, Germany and Poland in 2002, in the United Kingdom in 2007 or in the United States in 2005 with the passage of hurricane Katrina, cases of failures of 
structures demonstrate that a policy based only on protection is not enough to make it possible for a territory to overcome flooding. While some countries have chosen to reinforce the standards of protection provided by their structures, such as the Netherlands (Delta Plans I and II), others are exploring the possibilities offered by adapting installations in sectors that are not protected by dikes (case of the current project for greening the south of Manhattan in New York following Sandy).

\subsection{Developing poorly in a flood prone area is irreversible}

Designing an installation taking into account the flooding hazard is all the more important in that it is difficult to adapt a posteriori a building that might have been constructed without having taken this hazard into account for technical reasons (difficulty in transforming a single-storey individual house into a dwelling on piles) as well as for financial and/or social reasons.

In effect, a number of factors can explain why owners do not take measures making it possible to reduce the vulnerability of their dwelling. An English study revealed that the principal obstacle was the overly expensive cost of these measures. This can be explained by the fact that an owner is not certain that the measures taken will be profitable if his dwelling is not flooded during the period he lives in it. Another obstacle concerns the difficult choice between all the possible measures for adapting his dwelling. As owners often have little expert knowledge of these measures, they do not know which one to prioritise in function of the characteristics of the flood hazard. To these limits are also added the fear of seeing the appearance of the dwelling deteriorate and thus the value of their property declining when the time comes to sell. Lastly, other psychological factors may intervene such as denial of the risk, i.e. refusal by the owner to remember that he is living in a flood prone area once he sees these measures (Table 1).

\subsection{Climate change is forcing our cities to adapt}

Cities are subject to changes including those that are linked to the climate. On the coasts, the risk of coastal flooding is expected to increase with the rise of the sea level. It is estimated that 400,000 persons in Europe might be forced to leave their dwelling between 2050 and the end of the $21^{\text {st }}$ century. Concerning flooding by rivers, there still exists numerous uncertainties as to how the hazard will develop, but the annual average cost of floods could reach tens of trillions of euros by 2100 and concern 800,000 Europeans each year, particularly in France, the United Kingdom and Hungary [5-6].

The question of adapting urban installations to these changes thus arises compellingly. It is necessary to think about a variety of construction methods that can make buildings see their uses change. Moreover, in certain cases relocating infrastructures along the coastal areas is a necessary solution due to the major phenomenon of erosion (Hérault, Baie de Somme in France).

For all of these reasons, it is necessary to ponder how flooding in development plans in our current cities is to be taken into account. A number of projects are doing this already by setting up certain principles.

\section{Identified principles for development}

The principles presented come from the experience of cities located in France (Bordeaux, Saint-Pierre-desCorps, Romorantin-Lanthenay, Angers, Vitry-sur-Seine, Périgueux, Rennes, Blois, Toulouse), Germany (Mainz, Hamburg, Frankfort, Andernach), Netherlands (Rotterdam, Dordrecht, Nijmegen, Amsterdam), United Kingdom (Hackbridge), South Korea (Seoul), the United States (Yonkers), Japan (Tokyo). These examples are intended to outline new prospects for the urbanisation of flood prone areas in these cities.

\begin{tabular}{|l|c|c|c|}
\hline & $\begin{array}{c}\text { Agree } \\
\%\end{array}$ & $\begin{array}{c}\text { Disagree } \\
\%\end{array}$ & $\begin{array}{c}\text { Neither / } \\
\text { don't } \\
\text { know } \%\end{array}$ \\
\hline I feel it would be too expensive & 57 & 25 & 18 \\
\hline Collective measures have already been put in place & 42 & 35 & 23 \\
\hline I don't think I would be able to choose the right way to protect my home & 27 & 53 & 20 \\
\hline My home is covered by insurance so I don't need to worry & 27 & 63 & 10 \\
\hline It would make my house look odd & 27 & 57 & 16 \\
\hline I want my home to feel comfortable and look attractive & 26 & 58 & 16 \\
\hline If I'm selling my home, I don't want people to see it's at risk of flooding & 24 & 59 & 17 \\
\hline I don't think I'm going to live here much longer & 20 & 66 & 14 \\
\hline I don't want to be reminded of the risk of flooding & 17 & 78 & 5 \\
\hline
\end{tabular}

Table 1. Householders' responses when asked if they agreed with various reasons for not putting mitigation measures in place, in DEFRA at al., Developing the evidence base for flood resistance and resilience, 2008. 


\subsection{Integrating levees and other protective structures into urban development}

The first principle consists of integrating dikes into the urban development. Several types of situation have been highlighted following the study of a number of practices: e.g., super levees in Tokyo and in Toulouse (France), multi-functional dikes in Rotterdam and Dordrecht (Netherlands), flood protection barriers (mobile protective systems) in Andernach (Germany).

\subsubsection{Super levees}

This solution is aimed at meeting the problem of the breaching of dikes. It consists of banking up a dike up to the crest over a distance sufficient for the slope of the newly developed land to be slight (e.g., 3\%, Figure 1).

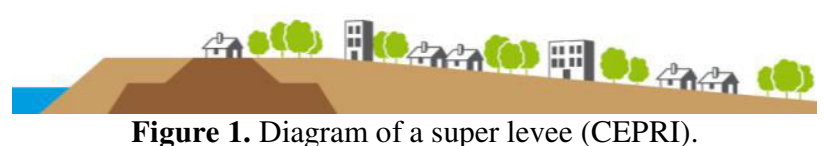

From a technical point of view, the super levee avoids the potential rupture of a dike on the section concerned. The dike is strengthened and transformed. This represents a guarantee of security in relation to the risk of breaching. On the other hand, this procedure does not prevent flooding of the urbanised area behind the dike due to overflowing.

This approach has been under consideration in Tokyo since 1987 in order to find a solution to the problem of the fragility of the dikes protecting densely populated areas along the Arakawa River and located beneath sea level. The project was authorised in 2001 and then modified in 2011 due to the very high costs generated, notably by relocating the inhabitants whose dwellings had to be moved. In Toulouse, 600 dwellings were constructed on the filled-in dike in the Sept Deniers neighbourhood which is exposed to the risk of the Garonne overflowing its banks. These luxury buildings have a direct access to the crest of the dike which is laid out for cyclists and pedestrians.

\subsubsection{Multi-functional dikes}

Another solution consists in building multifunctional dikes. This type of installation makes it possible to provide a response to the problem of availability of land, which is often rare and expensive in densely populated urban centres. This involves considering that the dike can have several uses: in addition to its use for protection, it can also house other urban functions such as transport (example of roads built into the body of the dike in the Boompjes City Balcony project in Rotterdam or on the crest of the dike) or shopping centres located into the dike, for example. Some buildings used for housing are also used as dikes (Voorstraat Dike in Dordrecht).

While this solution has the advantage of reconciling protection and urban development, it nevertheless raises the question of who is responsible for the management of such a structure. Multiple uses involve the intervention of multiple players on the multi-functional dike. This may result in increasing the attention devoted to dike management and its supervision. However, it can also make the distribution of roles complex, particularly in case of a crisis. The process also raises a number or technical issues bearing on the capacity of a dike to contain roads, for example, in the body of the structure while at the same time continuing to efficiently ensure its function of protection.

\subsubsection{Mobile protective systems}

A third possibility for integrating protective structures into the urban space concerns mobile protection systems: vertical wall barriers, dihedral structures, flexible liners, water gravity dams, big bags gravity dams, water absorbent bags [7-8]. These systems are interesting to the extent they can be installed before a flood occurs and then removed once the water has been evacuated. They represent an alternative to constructing a permanent dike. They also have the advantage of not deteriorating the urban landscape, which may sometimes be classified and preserved for historical, architectural or patrimonial reasons. Other than the impact on the urban landscape, a dike several metres high would also have the disadvantage of cutting inhabitants off from the waterways or the sea, which does not incite them to live with the water.

However, these mobile protective systems have a number of disadvantages linked to their implementation. To be correctly installed, they often require time as well as a good knowledge of the place they are stored at. In case of alert times that are too short, some processes may not be installed in time. Moreover, installing them requires know-how, something that might be forgotten if flooding is not very frequent or if trained personnel leaves. In order for the investment to be profitable for the community, these systems must thus be used frequently.

Last, most of them are effective if the water level does not exceed a certain threshold (depending on the type of system chosen). For some types of flooding, these systems are thus not highly recommended [9].

\subsection{Leaving more room for the water}

This principle consists in giving or in giving anew more space for the water on a sector in the process of urban renewal. In general, the solutions identified are of two types: either they hold back the water runoff without aggravating the risk of flooding, or in certain particular cases they go so far as to reduce the risk.

\subsubsection{Without aggravating the flood risk}

Installations intended not to aggravate the risks can take on various forms. Some require no construction of buildings: e.g., city parks, green spaces, sports grounds with light athletic equipment. Developing a vast park on 
the embankments of Bordeaux along the left bank of the Garonne takes account of this principle.

Other projects integrate this principle while preserving the water runoff capacities beneath building. One example in particular can be cited in the city of Romorantin-Lanthenay (France) where collective housings in the Matra neighbourhood have been constructed over openwork parking spaces and where houses have been built on piles. The streets in the neighbourhood are oriented in the direction of the River Sauldre waterway to allow more rapid evacuation of the water in the event of a 100-year flood.

\subsubsection{By reducing the flood risk}

While some projects do not modify the flood risk, others are intended to reconcile reduction of the risk and urban development. This is the case of the project in Nijmegen, included in the programme "Room for the River" [10]. The purpose of the project was to broaden the bed of the river Waal in order to reduce the water level in case of major flooding. The project was realised in several stages: moving back the dikes on the right bank, expropriation of some fifty homes, creation of a discharge canal in order to allow the water to run off year round, development of an island in the centre of the river bed and construction of a bridge joining the two banks and the newly created island (Figure 2).
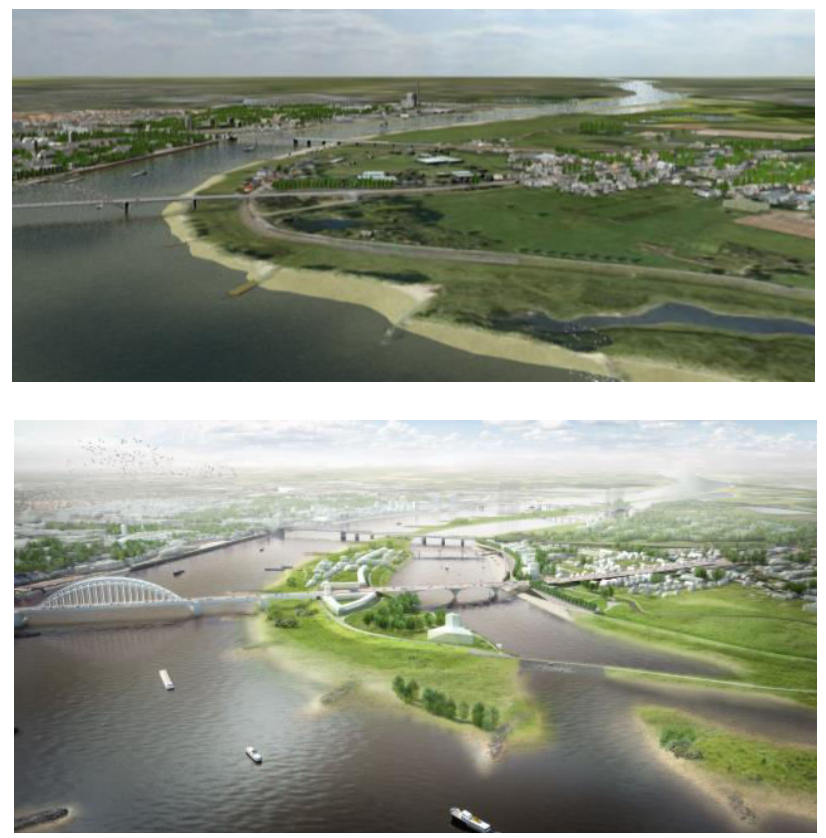

Figure 2. Drawing of the proposed creation of a discharge canal in order to broaden the river in Nijmegen (before and after) (Nijmegen City).

Other processes can also reduce the risk such as the demolition of urban structures: deconstruction of pipework, daylighting of buried waterways, etc. A number of large-scale projects illustrate this principle, notably the demolition of the expressway in Seoul. The purpose of this demolition is to find an alternative to the upkeep costs of the expressway, which is in a poor state.
The city decided to rehabilitate the river Cheonggyecheon over a distance of $6 \mathrm{~km}$ by undertaking a vast urban renewal programme starting in 2002. This development was designed to protect the city from a large-scale flood (recurrent every 200 years). Compensation for this development (estimated cost at around 260 million euros) resulted in the creation of a new business district near the river focused on the new technologies economy [11].

Whatever the solution for development adopted (reduction of the risk or not), it is beneficial for a project to take into consideration the room left for water.

However, in the case of solutions aimed at reducing the risk, it is indispensable to have a precise knowledge of the hydraulic impacts both upstream and downstream of the project.

\subsection{Locating uses according to their degree of vulnerability}

This principle is the one that seems most obvious for urban planning decision-makers. It consists in thinking through the layout of activities and infrastructures in function of their vulnerability in relation to the flood hazard. Concretely speaking, application of this principle requires proceeding by steps.

First, it involves defining which activities would generate the most vulnerability for the territory in case of flooding. Without being exhaustive, it is possible to cite a number of infrastructures that are indispensable in order for a city to function: infrastructures that might cause damage to people (hospitals, nursing homes, dwellings without a shelter level, etc.), those that are necessary for crisis management, civil security, defence, informing the population (communication platform) and assistance to victims, those that are indispensable for the operation of networks, servicing the economy (financial centres, banks), those that might cause additional damage (pollution, epidemics), activities necessary for post-crisis reconstruction (construction industry, road repairs, waste collection sites, etc.), infrastructures necessary for getting things underway again on the territory administratively, economically and socially (businesses, shopping centres, schools, courts, local public services, etc.) [12].

This phase is accompanied with a diagnosis making it possible to identify the activities and critical infrastructures for the territory [13]. European directive 2008/114/EC of 8 December 2008 requires member states to inventory the European critical infrastructures by privileging those that might result in victims, economic effects and consequences for the population [14]. It concerns only energy and transport. Some countries, such as France, also identify sewerage, the production or distribution of water for human consumption and electronic communications networks open to the public as well as critical infrastructures (Domestic Security Code). Healthcare facilities, fire stations, Gendarmeries and decision-making centres for crisis management. 
Second, once the activities most vulnerable for operating cities and critical infrastructures have been inventoried, it is possible to think about their implantation. In the United Kingdom, the "Planning Policy Statement 25 (PPS25): Development and Flood Risk" forms part of the British national policy for the management of flood hazards. This national framework identifies four types of risk to which four zones correspond. It then defines what uses can be implanted in these various zones according to their vulnerability. In 2009 it was replaced by the National Planning Policy Framework, based on a number of foundational principals taken over from the PPS25.

In practice, the implantation of activities can take place horizontally, i.e. it can distribute activities according to the levels of risk. This comes down to moving the most critical activities away from very highrisk zones, for example. This can also take place vertically which, schematically, means "piling" activities on one another as though they were found in a building where the last floor would be devoted to the most vulnerable activities, out of reach of the strongest risk. In both cases, this means protecting critical infrastructures from water so as to preserve their operation for the territory in case of flooding. One illustration bringing together both types of location (horizontal and vertical) is the principle of terraces (Figure 3). This makes it possible to elevate the natural level of the terrain in a stepped manner and to distribute uses on the various levels, the last being the highest and also the one farthest from the high-risk area and the one housing the most sensitive activities.

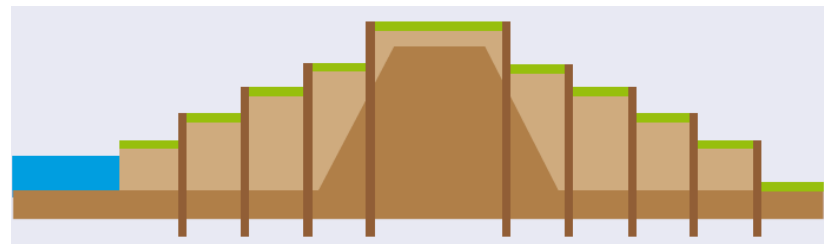

Figure 3. Drawing illustrating the example of arrangement in the form of terraces (case of a multifunctional dike) (CEPRI).

This procedure is the one imagined at the time of the initial reflection on the project in Ardoines in the Paris area (Vitry-sur-Seine, France). Three different levels of terraces were intended to house three types of use. The first level was that of the banks of the Seine for housing recreational activities. The second, higher than the banks, was to accommodate dwellings and offices. It was liable to flooding only in case of 100-year flooding.

Finally, the last level, higher than the others and liable to flooding only in case of exceptional flooding, was to accommodate industrial companies and equipment identified as strategic for the greater Paris area. This project required extensive land capacities and a cost such that it had to be reviewed. Reflection was focused more on district management in case of crisis, giving priority to keeping the structuring axes of the district (roads) and networks out of water in order to enable the inhabitants to evacuate autonomously in the event of major flooding of the Seine [15-16].

\subsection{Designing and constructing adapted/resilient buildings}

This principle is used rather currently today in most projects. It can be broken down in the form of different construction techniques according to the strategy desired for the building: avoiding water, resisting water or giving way to water.

\subsubsection{Avoiding water}

The first strategy consists in preventing water from penetrating the building. The most current techniques consist in elevating the building by constructing it on piles over a garage, over a crawl space or on a mound. It is thus that the districts of Hamburg, Frankfort (Germany) and Saint-Pierre-des-Corps and RomorantinLathenay (France) were designed.

This strategy has the advantage avoiding all potential direct damage to the building, since the building is not flooded. However, it does not ensure inhabitants that they can remain in their dwelling during the flood. The building may be isolated and uninhabitable if the networks are no longer in working order (flooding of roads, interruption of energy networks and telecommunication, etc.).

Other techniques also exist: floating and amphibious buildings. Floating constructions are numerous in the Netherlands, where there is a question of available land for new constructions. Research is currently underway in order to make it possible for floating platforms to bear heavy structures while reducing the number of materials to make these constructions more economical.

Amphibious buildings also represent an interesting technical response in delta zones, for example, which are subject to frequent flooding. In effect, this is a costly method that is profitable if it is regularly subjected to flooding. The building is constructed the same way as anchoring boats: they rise and fall according to the variation in water level along a guidance shaft.

All building techniques must be adapted to the type of flooding concerning the area where the buildings are constructed and to the cultural identity of each city.

\subsubsection{Resisting water}

Another strategy consists in slowing down or even preventing water from entering the building. This is an intuitive solution: when there is flooding, this is a strategy which is very often implemented by inhabitants who wish to protect their dwelling by using temporary or permanent obstructing systems (cofferdams, sandbags, low walls, etc.). The advantage of such a strategy is that it can be adapted to already existent buildings.

However, this protection using systems that are often temporary is effective only under certain conditions. The maximum water level in case of flooding must not be more than one metre, since above that the pressure exerted on the building is too strong and may destabilise the structure. The duration of the flood must 
be limited (less than 48 hours), since after a certain time it is difficult for temporary systems to keep water from entering unless the first level of the floor is designed as a perfectly waterproof coffer. The alert time must also be sufficient to enable the occupants of the building to install temporary systems. This presupposes that the occupants of the building are present at the time of the alert and that they are available, know where the material is stored and know how to install it. It is thus preferable that this strategy be resorted to in areas where floods are frequent so that know-how will be preserved. In any event, it is probable that at a given moment water will run into the building. For this reason, a pumping system must be provided for to ensure that the building can be emptied if need be [17].

\subsubsection{Giving way to water}

A third strategy can be implemented when it has not been possible to keep the buildings out of water and when the characteristics of the flood prevent resorting to the strategy of "resisting": giving way to water, i.e. letting water enter the building. This is a solution of last resort, since it can cause much damage inside the building and may be difficult to for the inhabitants to accept. However, when a building is exposed to submersion of more than one meter of water for more than 48 hours, this is a solution to take into consideration. But it necessitates designing the level that will be flooded with materials resistant to water or materials that are easily replaceable. Raising the levels of the networks, notably electrical networks, is indispensable in order for the building to become functional rather quickly after the water has passed.

All of these strategies require having a good knowledge of the parameters of flooding in order be able to choose the most appropriate strategy from a technical and economic point of view.

\subsection{Ensuring that the networks are in operating order}

This principle aims at identifying ways to design networks in order for them to meet the current needs of the population and also in case of flooding and during the post-crisis phase. The networks concerned are roads, electricity, drinking water, gas, urban heating, telecommunications, public transport, waste removal, sewerage. A number of strategies can be implemented simultaneously in order for the networks to keep operating. Some are more favourable to certain types of network. However, setting up some strategies may prove difficult or even impossible on existing networks and will be more pertinent when new networks are created.

\subsubsection{Strategy of avoidance}

This strategy consists in not exposing the network or its various components to water. It can be implemented horizontally, i.e. setting up certain installations outside the flood prone area. This can concern specific installations such as waste treatment plants, hydrocarbon reservoirs, stations and gas distribution stations, for instance. However, in floodable urban renewal areas, this strategy can be better applied vertically, i.e. by raising certain installations such as electrical transformation stations. Distribution can also take place aerially for electricity, telephony, urban lighting, transport (road, rail, pedestrian). However, questions of aesthetics and of encumbering public spaces in dense urban areas arise with this strategy. In Mainz (Germany), the project in the "Zollhafen" district provides for raising the main road in order to guarantee accessibility to the district in case of flooding, particularly for the rescue services [18].

\subsubsection{Strategy of sturdiness}

This solution aims to prevent the network not be deteriorated by the presence of water. It can be done in various ways. First, it is possible to improve the solidity of the network by using for example materials making it possible to avoid breaches, chipping or the effects of the Archimedes principle. The example of multi-network galleries is an interesting example. This involves constructing an underground gallery that can house various urban networks (drinking water, wastewater treatment and rainwaters according to the topography, gas, electricity, telecommunications, etc.). A number of galleries of this type exist in the Czech Republic, notably in Prague which has a network $90 \mathrm{~km}$ long. During the 2002 flooding, the galleries sustained very little damage, contrary to the surface infrastructures [19]. Second, it is possible to improve the waterproofness of the network (notably canalisations, cables) or to implement temporary arrangements. Another procedure is that of desensitisation, as for example using optical fibre which is not affected by contact with the water, contrary to copper networks (conductor of electricity), for example [20].

\subsubsection{Strategy of meshing}

This third strategy consists in enabling the city to benefit from networks that can continue to function despite internal malfunctions or limiting disturbances to the most restricted sectors possible. It can consist in diversifying the sources supplying the networks or their outlets. For example, in the United Kingdom, the Felnex district project in Hackbridge (suburb of London) in the Life project, would be supplied using several sources of energy: photovoltaic panels, biomass, heat pumps and a mini hydroelectric power station producing less than $100 \mathrm{kw}$. Different types of renewable energy have been chosen in function of their compatibility with the flooding hazard. They will be set up in the floodable area and are able to function in the event that the Wandle River overflows (the duration of immersion is estimated at less than one day with water levels between $0,5 \mathrm{~m}$ and $0,9 \mathrm{~m})[21]$.

Increasing the number of itineraries of supply (or redundancy) also makes it possible to ensure meshing of the city. For example, in Hamburg, the Hafencity project 
is planning for the rehabilitation of a neighbourhood of 157 ha located in the city centre and situated on an island. It is intended to house 12,000 new inhabitants and 45,000 jobs. To ensure accessibility of the new neighbourhood with the rest of the city on a permanent basis, the road network is provided with six bridges. This network has been designed in order to remain operational during flooding in order for inhabitants of the neighbourhood to be able to join the city centre by food. During normal periods, it allows pedestrians and cyclists to travel between the city and Hafencity.

A last possibility is to compartmentalize, i.e. avoiding that part of the network affected by a flood spreads throughout the network. For example, allowing the part of the network affected by flooding to stop operating so as to prevent the entire network from being impacted, particularly the part of the network which is not in the flood prone area.

\subsection{Creating Smart Shelters}

The last principle aims at proposing solutions to facilitate crisis and post-crisis management during and after a flood event. It is based on the "smart shelter" concept, developed within the scope of the European project FloodProbe [12]. This concept is based on the fact that in case of flooding, part of the population does not evacuate the flooded territory when the alert is given. This was the case with the passage of hurricane Sandy in New York in October 2012: around 15\% of the population located in the area exposed to flood risk refused to evacuate, thinking that the consequences of the hurricane were overestimated [22].

In other cases, the inhabitants follow the order to evacuate, but the emergency housing is not organised under good conditions. The places for emergency housing
The Smart Shelter concept aims to provide a response to these situations by contemplating infrastructures or buildings that would be designed in case of flooding so as to house inhabitants that might have evacuated the flooded area. Moreover, this principle also makes it possible to look at these places as resupply points for medical material, food and basic necessities accessible in case of flooding and during the post-crisis period.

Designed to meet these objectives, these infrastructures are thus intended to reduce the vulnerability of one or more existing neighbourhoods. The FloodProbe project even envisages meshing the territory of a city with various well-adapted places of shelter possibly linked together (roads, footbridges). This involves these places possibly being established in areas that might be subject to flood risk, as close as possible to the stricken population. It also means that these places must be adapted to the presence of water (construction processes taking account of flooding and continuity of operation of the networks) so as to be able to meet the vital needs of the sheltered population. They must be accessible and their dimensions must take into consideration housing the population (number of beds, toilet facilities, eating areas, play areas for children, etc.) (Table 2).

These buildings thus present a number of characteristics that extend beyond the capacities of a traditional building. They must be adapted to a flood event, they might serve as a shelter in case of flooding and must provide permanent accessibility. Therefore it represents an additional cost, estimated at 22\% [23].

Now, this cost could be amortised due to the fact that it might be used for several purposes at the same time during normal periods, at times of flooding and during the post-crisis period. This building would thus be

\begin{tabular}{|c|c|c|c|c|c|c|c|}
\hline \multicolumn{8}{|c|}{ Smart Shelter Capacity } \\
\hline \multicolumn{2}{|c|}{ Smart Shelter building type } & \multicolumn{2}{|c|}{ Cinema } & \multicolumn{2}{|c|}{ School } & \multicolumn{2}{|c|}{ Conference Hall } \\
\hline Gross Floor Area & & 5000 & $\mathrm{~m}^{2}$ & 5000 & $\mathrm{~m}^{2}$ & 5000 & $\mathrm{~m}^{2}$ \\
\hline Spatial Requirements & $10 \%$ & 500 & $\mathrm{~m}^{2}$ & 500 & $\mathrm{~m}^{2}$ & 500 & $\mathrm{~m}^{2}$ \\
\hline Total Gross Floor Are & & 5500 & $m^{2}$ & 5500 & $m^{2}$ & 5500 & $m^{2}$ \\
\hline $\begin{array}{l}\text { Useable net. Area } \\
(50 \% / 65 \% / 80 \%)\end{array}$ & & 2750 & $m^{2}$ & 3575 & $m^{2}$ & 4400 & $m^{2}$ \\
\hline Capacity short-term & $1,86 \mathrm{~m}^{2} /$ pers. & 1478 & pers. & 1922 & pers. & 2365 & pers \\
\hline Capacity long-term & $3,72 \mathrm{~m}^{2} /$ pers. & 739 & pers. & 961 & pers. & 1182 & pers. \\
\hline
\end{tabular}

Table 2. Usable floor space (in $\mathrm{m} 2$ ) for shelters (FloodProbe project).

are often improvised or generally not designed to shelter a large population for several days. This was the case for example in New Orleans in 2005 following the passage of hurricane Katrina. 77,000 persons did not evacuate the city when the flooding took place. Some of them took refuge in the Superdome football stadium planned by the authorities as a shelter of last resort. The sanitary and safety conditions deteriorated rapidly, generating a humanitarian crisis while the stadium began to be flooded. designed to have multiple uses which are variable over time and according to circumstances. It can be any type of infrastructure (school, gymnasium, hospital, airport, etc.). For example, in the Life-Project (UK), the Felnex district project in Hackbridge proposes to construct a school in the centre of the neighbourhood exposed to a flood with a low return interval (1/1 000 years). It is planned that the school will be raised and that it will serve as a shelter to house the population of the neighbourhood in case of flooding. The interest of the project lies in building the school in the flood prone area 
in conjunction with the power production facility located in the vicinity. It can be used as a shelter but also as a central point for managing the power production system, resupplies, crisis and post-crisis management and informing the population of the neighbourhood in case of flooding [24].

Other projects are experimenting with this still marginal concept, notably in the Netherlands (Rotterdam) and in France (Orléans).

These six principles present advantages from technical, economic, political, landscaping, legal and social points of view. In some circumstances, they can also have disadvantages which it is suitable to anticipate in order to choose the combination of principle that will be most effective for the territory concerned.

Effectively these principles are not exclusive of each other. They can be combined on different scales in a city. For example, the city of Dordrecht is contemplating a strategy for developing its territory by integrating dikes. It is also considering, on other sectors that have not been embanked, designing projects with buildings and networks adapted to the presence of flood risk ("Stadswerven" area).

\section{Implementing the principles}

Despite the relative lack of perspective on the implementation of certain principles such as the smart shelters concept, it seems important to take into account a number of factors when designing development projects integrating these principles.

\section{1 "Multifunctionality" or multi-use concept}

This dimension seeks to address the problem of the cost of buildings adapted to the flood risk by proposing to design infrastructures that provide multiple benefits. It can be illustrated by multifunctional dikes and smart shelters whose purpose is to concentrate several uses on a same structure. Uses can be multiple according to the various phases: normal period, period of flooding and post-crisis. The interest is to this dimension as from the time a structure or a building is designed, since it is more expensive to adapt a structure or a building to several functions a posteriori.

\subsection{Avoidance, solidity, meshing}

These characteristics concern especially networks, but they could be applied to any activity necessary for operating a city in order to continue to provide a minimum level of services to the population in case of flooding and during the reconstruction phase. For example, smart shelters must continue to provide vital needs for the population in case of flooding and during the post-crisis phase. The FloodProbe project suggests that this type of infrastructure can be set up any various neighbourhoods of a city in order to reduce the city's vulnerability overall by possibly meshing its territory with several smart shelters. These shelters can be linked together by out-of-water access roads or footbridges.

\subsection{The culture of risk}

This component appears to be essential in the process of accepting flood risk. For urban planning decision-makers, it involves integrating existence of the risk into projects with architectural and landscaping forms recalling the presence of the risk. Thus, the principle consisting of leaving more room for water directly influences inhabitants' perception in relation to the presence of water in the city (examples of daylighting waterways that were formerly canalised and buried). The principle of integrating mobile protective structures into the development also makes it possible to preserve the link between the waterway or the sea and the inhabitants which contributes to forging a certain culture of risk and population acceptance.

\subsection{Territorial equity}

As a pillar of sustainable development since 1992, equity appears to be an important factor in decisions on development when considering the flood hazard. In order to take account of this factor, the notion of scale is important when implementing principles. What principle will be integrated into a project on the scale of a neighbourhood? What repercussions will this principle have on surrounding neighbourhoods, or even on the city as a whole? For example, deciding to build a protective dike in a sector and choosing not to construct one in another sector raises the question of territorial equity with regard to the flood hazard. The principle aimed at reducing the vulnerability of infrastructures, just as keeping the networks and the smart shelters operating, provides an answer. In the case of smart shelters, the purpose of the principle is to reduce the vulnerability of the neighbourhood and can even go as far as reducing the vulnerability of the surrounding neighbourhoods. It is thus through the combination of principles on different scales that that a city can meet this demand for territorial equity faced with the flood hazard [25].

\subsection{Sustainable development}

Through this dimension, it is adapting the city to changes, notably climate changes, that is concerned. Taking flood hazards into account in the development of a city comes within a truly sustainable approach. It involves implementing innovative solutions making it possible to ensure the effectiveness of economic development through reducing the vulnerability of economic activities, social equity and the quality of the environment over the long term.

The principle consisting in giving more space to water and in that of maintaining operation of the networks come within this objective. The first illustrates the current tendency to give more space to nature in the city such as the creation of secondary branches of 
waterways, which sometimes involves the large-scale relocation of inhabitants.

The principle on networks also comes within a sustainable conception when energy diversification is concerned. This makes it possible to ensure power supply in case of flooding which is not linked to a single source of energy and that also favours recourse to renewable energies or alternatives to fossil energies.

\subsection{Crisis management}

This involves an essential component to be taken into account when the principles are implemented. It means anticipating potential disturbances in case of flooding in planning policies. But it also means that it is necessary to know the crisis management plan under consideration by the authorities in case of flooding in order to provide a pertinent technical response. For example, if it is foreseen that the inhabitants of a neighbourhood remain and do not evacuate due to a very short alert time (flash flood event), it is necessary to plan for a level of sheltering in the buildings.

On the other hand, if it is considered that the inhabitants will evacuate by themselves, the roads and transport arteries must be dimensioned so as to allow this autonomy (e.g., heightening, network of footbridges between buildings, removable bridges, etc.). In the example of the "Westhafen" neighbourhood in Frankfort, built along the Main River, the buildings were constructed on piles parallel to the river. Offices have been fitted out on either side of a marina located in the heart of the neighbourhood (Figure 4).

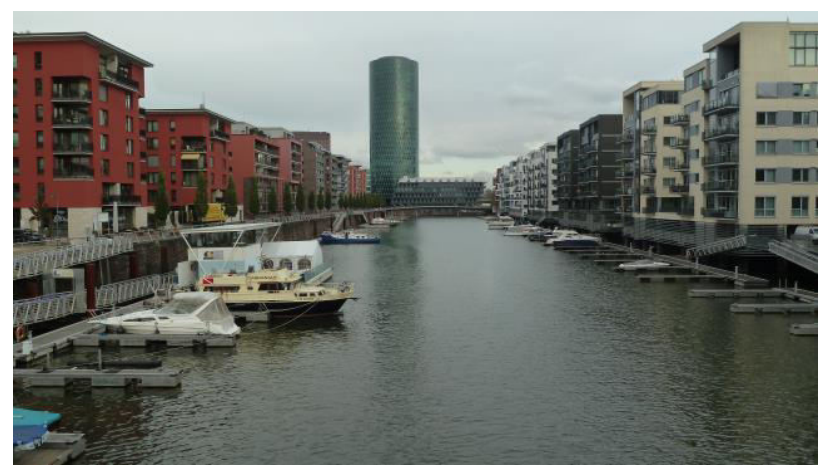

Figure 4. The Westhafen neighbourhood in Frankfurt (CEPRI).

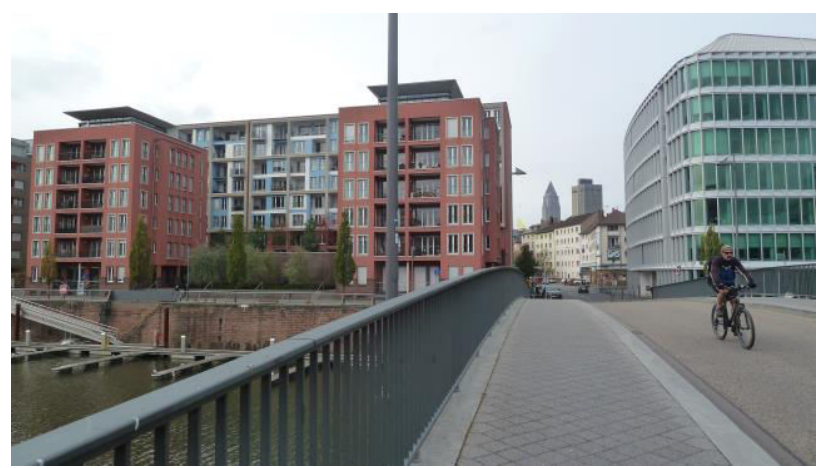

Figure 5. The footbridge linking the Westhafen neighbourhood to the city centre of Frankfurt (CEPRI).
To connect the neighbourhood to the town centre, two bridges at the far ends of the marina were built. They thus make it possible to evacuate the inhabitants of this neighbourhood in case of flooding by the Main (Figure 5).

\section{Conclusion}

Numerous projects that have been analysed demonstrate that technical and organisational solutions exist for integrating flood risks into urban planning. They can be grouped into six principles which present a number of advantages from a technical, economic, social, political, legal and landscaping point of view. According to the scale on which they are implemented (building, neighbourhood, grouping of neighbourhoods, city and beyond), these principles can be combined. For example, the principle of smart shelters brings together three other principles: deciding to locate a multifunctional infrastructure in a flood prone area, adapting it (avoiding, resisting or giving way), keeping the networks operating (accessibility, operating critical networks to meet the priority needs of the population in case of flooding and during the post-crisis phase).

According to the cities and the flooding hazards to which cities are exposed (overflowing of waterways, coastal flooding, rain runoff, flash floods, etc.), some principles will be more pertinent than others. However, it is important to take a number of factors into account for their concrete application such as multi-use, the culture of risk, sturdiness, avoidance, meshing, territorial equity, sustainable development and crisis management.

All projects analysed, realised or under consideration demonstrate that this way of adapting the territory to the risks of flooding is innovative and would make it possible to reduce the vulnerability of many cities. However, it would be worthwhile to experiment more on the ground in order to be able to demonstrate its profitability over the medium and even the long term.

The question of paying for the cost of these developments, which the concept of multi-use seeks to answer, is primordial in order for these developments to effectively be realised.

\section{References}

1. Faytre L. (2013). Logement : quelle exposition du parc francilien en zone inondable ? Note rapide $n^{\circ}$ 634.

2. CGEDD (2015). Risques et marchés immobiliers. L'influence du risque inondation sur le prix des logements. Le Point sur $n^{\circ} 214,4$ p.

3. Slomp R., Rijkswaterstaat (2012). Le cadre législatif et organisationnel de la gestion du risque d'inondation aux Pays-Bas. Audition au Sénat, Paris 29 mai 2012.

4. MEEM (Ministère de l'environnement, de l'énergie et de la mer), http://www.developpementdurable.gouv.fr/Parc-des-ouvrageshydrauliques.html [18/02/2016] 
5. CEPRI (2015). Changement climatique, vers une aggravation du risque inondation en France et en Europe?, 11 p.

6. Brown S. et al. (2011). The impacts and economic costs of sea-level rise on coastal zones in the EU and the costs and benefits of adaptation, Summary of sector results from the ClimateCost project, Technical Policy Briefing Note 02, 42 pp.

7. Salagnac J.-L. (2007). An Overview of Flood Protection Barriers, Advances in Urban Flood Management, pp.453-459

8. Salagnac J.-L., Marchand D., Florence C., Delpech P., Axes J.-M. (2014). Impacts des inondations sur le cadre bâti et ses usagers, Rapport final, $46 \mathrm{p}$.

9. CEPRI (2015). Comment saisir les opérations de renouvellement urbain pour réduire la vulnérabilité des territoires inondables face au risque d'inondation? $130 \mathrm{p}$.

10. Ruimte voor de Waal Nijmegen, www.ruimtevoordewaal.nl [18/02/2016]

11. Lecroart P. (2013). Séoul, Cheonggyecheon Expressway. La Ville après l'autoroute : études de cas.

12. Crochet E., MEDDTL (DGPR, DHUP, CGPC) et GEPP. Recommandations pour le recensement et la classification des bâtiments, équipements, installations et ponts de catégorie d'importance IV, in :

www.planseisme.fr/IMG/pdf/guide_classe_d_vf_all egee.pdf

13. Escarameia M., Stone K., Van M., Zevenbergen C., Morris M. (2013). Guidance based on findings from the EU-funded Projet FloodProBE.

14. Council Directive 2008/114/EC of 8 December 2008 on the identification and designation of European critical infrastructures and the assessment of the need to improve their protection.

15. Etablissement Public d'Aménagement Orly Rungis Seine Amont.

16. J-Ph. Defawe J-Ph (2009). Les Ardoines, le projet phare de l'OIN Orly-Rungis Seine Amont entre dans sa phase opérationnelle. Le Moniteur, in: www.lemoniteur.fr/article/les-ardoines-le-projetphare-de-1-oin-orly-rungis-seine-amont-entre-danssa-phase-operationnelle-1021597

17. CEPRI (2009). Un logement «zéro dommage» face au risque d'inondation est-il possible ?, 54p.

18. See [9].

19. Sternadel J. (2008). Galeries multiréseaux. L’expérience de Prague. Travaux n857. Pp.29-38

20. CEPRI (2016). Le territoire et ses réseaux face au risque d'inondation. $86 \mathrm{p}$.

21. Baca Architects, BRE and Fulcrum Consulting, Halcrow Group Ltd, Cyril Sweet and LDA Design (2009). The Life-Project, Long-term Initiatives for Flood-risk Environments, 200 p.

22. Haut Comité français pour la défense civile (HCFDC), Secrétariat général de la défense et de la sécurité nationale (SGDSN) (2013). Retour d'expérience suite à l'ouragan Sandy sur la côte est des États-Unis.
23. Blom E.T., Zevenbergen C., Gersonius B., Van Son E. (2012). Smart shelter strategies - cost-effectiveflood preparedness, in Klijn and Schweckendiek, Comprehensive Flood Risk Management Research for Policy and Practice.

24. See [21].

25. See [9]. 